\title{
Levels of Zinc, Copper, Magnesium Elements, and Vitamin B12, in Sera of Schoolchildren With Giardiasis and Entrobiosis in Kashan, Iran
}

\author{
Mohsen Arbabi, ${ }^{1,{ }^{*}}$ Nader Esmaili, ${ }^{1}$ Karim Parastouei, ${ }^{2}$ Hossein Hooshyar, ${ }^{1}$ and Sima Rasti ${ }^{1}$ \\ ${ }^{1}$ Department of Medical Parasitology and Mycology, Faculty of Medicine, Kashan University of Medical Sciences, Kashan, IR Iran \\ ${ }^{2}$ Department of Medical Biochemistry, Faculty of Medicine, Kashan University of Medical Sciences, Kashan, IR Iran \\ ${ }^{*}$ Corresponding author: Mohsen Arbabi, Department of Medical Parasitology and Mycology, Faculty of Medicine, Kashan University of Medical Sciences, Kashan, IR Iran. \\ E-mail:arbabi4.mohsen@yahoo.com
}

Received 2014 November 1; Accepted 2014 December 31.

\begin{abstract}
Background:There are scant evidences between giardiasis and enterobiasis with human mal-absorption of micronutrient.

Objectives: The aim of the present study was to found out the changes in the serum zinc, copper, magnesium and vitamin B12 levels in schoolchildren infected with Giardia intestinalis and Enterobius vermicularis.

Patients and Methods: This case-control study was carried out among 359 children from aged 6-12 years old at 8 suburban public schools. Three stool examinations were done using standard techniques for identification parasitic infection. Fifty E. vermicularis and $37 \mathrm{G}$. lamblia infected individuals were enrolled as study groups. Serum levels of copper, zinc, magnesium were assessed by autoanalyzer and vitamin B12 levels were measured using gamma counter. ANOVA and paired t-test analyses were used to determine the association between infections and trace elements changes.

Results: The prevalence of $G$. intestinalis and E. vermicularis infections were $10.3 \%$ and $13.9 \%$, respectively. The serum zinc, copper and magnesium levels showed a significant decrease in individuals infected with G. intestinalis and E. vermicularis $(\mathrm{P}<0.05)$. Mean values of Giardia positive and negative groups for copper $143.65 \pm 16.51$ and $176.26 \pm 17.6 \mu \mathrm{g} / \mathrm{dL}$, zinc $62.26 \pm 16.06$ and $80.66 \pm 23.58 \mu \mathrm{g} / \mathrm{dL}$, and magnesium $1.82 \pm 0.23$ and $2.01 \pm 0.16 \mathrm{mg} / \mathrm{dL}$, respectively. Mean values of Enterobius positive and negative groups for copper $145.55 \pm 26.84$ and $176.26 \pm 17.6 \mu \mathrm{g} / \mathrm{dL}$, zinc $72.7 \pm 17.92$ and $80.66 \pm 23.58 \mu \mathrm{g} / \mathrm{dL}$ and magnesium $1.93 \pm 0.11$ and $2.01 \pm 0.16 \mathrm{mg} / \mathrm{dL}$, respectively.

Conclusions: The results showed that giardiasis and enterobiasis decreased serum levels of copper, zinc and magnesium. Further studies are needed to clarify the actual mechanism governing the zinc, copper, magnesium and vitamin B12 giardiasis/enterobiasis interaction.
\end{abstract}

Keywords: Zinc, Copper, Magnesium, Vitamin B12, Iran, Giardia intestinalis, Enterobius vermicularis

\section{Background}

Intestinal parasitic infections have a worldwide distribution and constitute considerable public health problems especially in developing countries. Giardia lamblia and Enterobius vermicularis are one of the most common intestinal parasitic infections worldwide, that affect people particularly children in developing countries Africa, Asia and Latin America [1, 2]. Approximately 3.5 billion people are infected by intestinal parasites and more than 450 million children are ill because of this parasitic infection [1]. Current worldwide prevalence of giardiasis and enterobiasis among children under 10 years of age was to range from 15 - 20\% and 11.4 - 61\%, respectively [3, 4]. Apart from causing morbidity and mortality, infection with pathogenic parasites of intestine has known to cause iron deficiency anemia, growth retardation in children and other physical and mental health problems. Also, chronic intestinal parasitic infections have been about the spreading and severity of other infectious diseases of viral origin, tuberculosis and malaria [5]. Low levels of health education, poor individual and public health, poor drinking water, overcrowded conditions and poor environmental sanitation increase the prevalence of giardiasis and enterobiasis [6,7]. The main impact of human intestinal parasitic infections is its relation to trace elements and vitamin deficiency, which may have effects at the community level as regards work and productivity in adults and learning and school performance in children. Children who have suffered these deficiencies may give less attention to education and social skills irrespective of IQ (intelligence quotient) [8]. Trace elements regulate metabolic pathways and the immune response, as well as suppress the incidence of various diseases [9]. The most important vital elements in the human body are zinc, copper, magnesium and vitamin B12. Zinc is especially vital for the immune system functions and its depletion is associated with decline in lymphocyte and thymus functions. Due to its role in immune system functions, zinc deficiencies make infants suffer from acute diarrhea [10]. Zinc deficiency is another increasing public health problem. Its global prevalence was estimated at 31\%, ranging

Copyright (C) 2015, Zahedan University of Medical Sciences. This is an open-access article distributed under the terms of the Creative Commons Attribution-NonCommercial 4.0 International License (http://creativecommons.org/licenses/by-nc/4.0/) which permits copy and redistribute the material just in noncommercial usages, provided the original work is properly cited. 
Arbabi Metal.

from $4-73 \%$ across developing countries [11]. Zinc deficiency has been found to be caused by poor intake and malabsorption, and has been associated with growth retardation, neurosensory changes, impaired cognitive function, abnormal immune functions and death [12].

Zinc and magnesium also helps in the production of antibodies and T-cell and other blood cell activities [913]. Copper is essential for producing red blood cells, hemoglobin formation and absorption of iron and for the activity of various enzymes [14]. Copper and zinc are cofactors for cytosolic superoxide dismutase, and their decreasing levels affect on the activity of cytosolic superoxide dismutase. Superoxide dismutase is a metalloenzyme capable of scavenging superoxide radicals by catalyzing their dismutation to reactive oxygen species. Reactive oxygen species can cause peroxidation of lipids leading to damage of membrane permeability, loss of enzyme activity, DNA damage leading to mutagenesis, carcinogenesis and apoptosis of cell $[14,15]$.

Vitamin B12 and folate deficiency are related to cell proliferation and anemia. Also, vitamin B12 is involved in DNA synthesis [16]. The association between trace elements deficiency and G. intestinalis and E. vermicularis infection has scarcely been investigated and links are controversial [10, 13-16].

\section{Objectives}

The aim of the present study was to investigate the changes of the serum zinc, copper, magnesium and vitamin B12 levels in children infected with $G$. intestinalis and E. vermicularis in comparison to normal subjects inhabiting in Kashan, Iran.

\section{Patients and Methods}

This case control study was carried out on among 359 children aged 6 - 12 years old who attended various primary schools in Kashan, Iran. The study participants were selected using a multistage sampling method. Data were collected through house-to-house survey. Stool samples were collected in sterile clean stool cups from all individuals. Examination of fecal samples for detection of G. intestinalis cyst and/or trophozoite was done by direct wet smear and standard formol-ether concentration method immediately. E. vermicularis was diagnosed using the Graham technique [17]. One slide with cellophane tape was given from each student. Among the whole population a total 50 positive individuals for E. vermicularis were enrolled as study (positive) group and 37 children were chosen for case group who had only G. intestinalis infection. The control groups consisted of 37 (giardiasis) and 50 (enterobiasis) age and sex matched healthy volunteers according to the criteria described in the questionnaire.

Some questionnaires were completed by parents, including questions about records for malabsorption, analyzed parameter deficiencies, and infection with parasites. Both groups had no record of serum shortage of mentioned factors and malnutrition. Blood samples were collected from the case and control groups after taking parent's permission. The serum was separated from the clotted blood in both groups and kept in $-70^{\circ} \mathrm{C}$ freezer for further biochemical laboratory examination. All blood samples were measured for the amount of copper, zinc, magnesium and vitamin B12. Copper, zinc and magnesium levels were assessed by Ziestchem Diagnostics Kit and calorimetric endpoint method by autoanalyzer (BT 2000, Spain). Vitamin B12 levels were measured by DRG Diagnostics Kit, REF RIA-1990, (Germany) and measured by gamma counter system (Berthold LB 951, Germany). ANOVA and paired t-test analyses were used to determine the association between giardiasis and enterobiasis and trace elements changes (SPSS-17 for windows, SPSS Inc. Chicago, USA). P value less than 0.05 was regarded as statistically significant.

\section{Results}

Totally, 24 (34.5\%) individuals were found positive for at least one intestinal parasite. The prevalence of G. intestinalis and E. vermicularis infection were $10.3 \%(\mathrm{n}=37)$ and $13.9 \%$ $(\mathrm{n}=50)$, respectively. Sex was not associated with parasitic infections. No statistically significant difference of infection was noted among the age groups. The results of this study are summarized in Tables 1 and 2. In Table 1 mean serum levels of zinc, copper and magnesium in G. intestinalis positive is remarkably lower than $G$. intestinalis negative group $(\mathrm{P}=0.05, \mathrm{P}=0.0001$ and $\mathrm{P}=0.05$, respectively). In addition, there was no significant difference in serum vitamin B12 between both groups. Besides ranges of copper, zinc, magnesium and vitamin B12 distributions of $E$. vermicularis positive and E. vermicularis negative individuals was shown in Table 2 . Results clearly showed that the serum zinc, copper and magnesium levels decreased significantly in children with enterobiasis, but no significant difference in serum vitamin B12 between both the groups.

\begin{tabular}{|c|c|c|c|}
\hline Parameters & Giardiasis $^{\mathrm{a}, \mathrm{b}}$ & Control $^{\mathrm{a}, \mathrm{b}}$ & P Value \\
\hline Serum Zinc, $\mu \mathrm{g} / \mathrm{dL}$ & $62.26 \pm 16.06$ & $80.66 \pm 23.58$ & 0.04 \\
\hline Serum Cu, $\mu \mathrm{g} / \mathrm{dL}$ & $143.65 \pm 16.51$ & $176.26 \pm 17.60$ & $<0.0001$ \\
\hline Serum Mg, mg/dL & $1.82 \pm 0.23$ & $2.01 \pm 0.16$ & 0.02 \\
\hline Serum Vitamin B12, pg/mL & $525.75 \pm 138.40$ & $538.00 \pm 122.09$ & 0.74 \\
\hline
\end{tabular}


Arbabi Metal.

\begin{tabular}{|c|c|c|c|}
\hline Parameters & Enerobiasis $^{\mathrm{a}, \mathrm{b}}$ & Control $^{\mathrm{a}, \mathrm{b}}$ & P Value \\
\hline Serum Zinc, $\mu \mathrm{g} / \mathrm{dL}$ & $72.7 \pm 17.92$ & $80.66 \pm 23.58$ & 0.05 \\
\hline $\operatorname{Serum~Cu,~} \mu \mathrm{g} / \mathrm{dL}$ & $145.55 \pm 26.84$ & $176.26 \pm 17.60$ & 0.0001 \\
\hline Serum $\mathrm{Mg}, \mathrm{mg} / \mathrm{dL}$ & $1.93 \pm 0.11$ & $2.01 \pm 0.16$ & 0.05 \\
\hline Serum Vitamin B12, pg/mL & $514.75 \pm 142.96$ & $538.00 \pm 122.09$ & 0.54 \\
\hline
\end{tabular}

Values are presented as mean \pm SD

$b_{(n=50)}$.

\section{Discussion}

The present study showed $10.3 \%$ and $13.9 \%$ individuals were infected to G. intestinalis and E. vermicularis, respectively. The serum zinc, copper and magnesium levels showed a significant decrease in individuals infected with G. intestinalis and E. vermicularis. There was no significant difference between vitamin B12 levels between the two groups.

Intestinal parasitic infections such as Giardia and Enterobius are still an important public health problem and responsible for considerable morbidity and occasional mortality among the infected population throughout the world, mainly in specific geographical areas and among people with specific socioeconomic status. However some intestinal parasites, like Enterobius are still ignored, even though it can defect the grow and learning of the young population $[1,18]$. Intestinal parasites use carbohydrates, lipids, minerals, vitamin and other food sources of the host in order to essential energy of the life cycle [8]. Minerals have an important role in the metabolic and physiology of the human body, especially in the growing children. Several studies have been reported that elements such as copper, zinc and magnesium are vital for growth and development $[8,18]$.

They have a significant role in the structure of some cellular enzyme, different immunological process and the resistance to the free radical damage by stabilizing the cellular membrane [9]. Low serum levels of copper and zinc could causes harm in cellular and enzymatic roles $[19,20]$. Serum zinc levels were lower during protozoan infections. In addition, elevations of serum copper levels are noted in most of the acute and chronic parasitic infections [9]. The association of giardiasis and enterobiasis with the malabsorption of zinc, copper, magnesium and vitamin B12 remains controversial. In several studies conducted about trace elements in giardiasis has shown a significant decrease in zinc levels while there was an obvious increase in copper levels [8, 10, 12, 14]. However, in few reports there was no significant difference in serum levels of zinc, copper and magnesium elements between the two groups [21]. In contrast, a study showed mean serum levels of copper in Giardia positive, was significant upper than the Giardia negative groups [14]. Also in some investigation showed the mean serum levels of copper, zinc and magnesium in individuals with enterobiasis were significantly lower than in the control groups [21]. The present study, showed a significant decrease in zinc, copper and magnesium levels in G. intestinalis positive and E. vermicularis positive individuals compare to the control groups. Results obtained in our study are compatible and agreeing with result of other researches. As it was mentioned above zinc cannot be stored in the body, therefore it could be easily declined in the serum. However, 90\% of serum copper is stored in the bound form to the ceruloplasmin. Elevations of serum copper levels are observed in most of the infections in relation to fluctuations of ceruloplasmin as an acute phase reactant [13]. Vitamin B12 is involved in the synthesis of important biochemical transmitters in the brain and nervous system. Vitamin B12 is involved in the synthesis of DNA. It is especially important during growth and cell proliferation [22].

Vitamin B12 is important in the transport and storage of folate in the cells. Folate is also important in cell division and DNA synthesis. Folate must be digested by pancreatic juice in the duodenum, where G. intestinalis usually colonizes [23]. Damage of intestinal epithelium occurs by adherent trophozoites of $G$. intestinalis. It has been proposed as one important mechanism in the pathogenesis of infection. Giardiasis can cause vitamin B12 deficiency, bowel inflammation and interfere with folate absorption [9, 24]. Few studies showed B12 deficiency due to giardiasis [25]. However, some reports found normal absorption of folate during G. intestinalis infection. In this study, no significant difference was viewed between the G. intestinalis positive and G. intestinalis negative individuals and E. vermicularis positive groups compared to control groups.

Our results regarding trace elements, giardiasis and enterobiasis decreased serum, zinc and magnesium levels, while they no significant effect on serum levels of vitamin B12.

\section{Acknowledgements}

The authors would like to thanks Kashan University of Medical Sciences for their kind support and assistance. This study was financially supported through grant No. 8647 afforded by the Research Affairs of Kashan University of Medical Sciences, Kashan, Iran. 


\section{Footnotes}

Authors' Contribution:Mohsen Arbabi: design, parasitological analysis, statistical analysis and manuscript writing, Nader Esmaili: data collection, Karim Parastouei: biochemical analysis, Hossein Hooshyar: parasitological analysis and manuscript writing, Sima Rasti: manuscript writing.

Funding/Support:Kashan University of Medical Sciences.

\section{References}

1. Wegayehu T, Tsalla T, Seifu B, Teklu T. Prevalence of intestinal parasitic infections among highland and lowland dwellers in Gamo area, South Ethiopia. BMC Public Health. 2013;13:151. doi: 10.1186/1471-2458-13-151. [PubMed:23419037]

2. Zareborani M, Mirhandi F, Rezaeian M, Dashti N. Detection of the "Tim" gene of sheep using "Tim" Gene primers of Giardia of with human origin. Int J Vet Res. 2010;4(2):69-72.

3. Matthys B, Bobieva M, Karimova G, Mengliboeva Z, Jean-Richard $\mathrm{V}$, Hoimnazarova $\mathrm{M}$, et al. Prevalence and risk factors of helminths and intestinal protozoa infections among children from primary schools in western Tajikistan. Parasit Vectors. 2011;4:195. doi:10.1186/1756-3305-4-195. [PubMed:21981979]

4. Abbas NF, El-Shaikh KA, Almohammady MS. Prevalence of Giardia lamblia in diarrheic children in Almadinah Almunawarh, KSA. Taibah Univ Sci. 2011;5:25-30. doi:10.1016/s1658-3655(12)60035-1.

5. Nacher M, Singhasivanon P, Gay F, Phumratanaprapin W, Silachamroon U, Looareesuwan S. Association of helminth in fection with decreased reticulocyte counts and hemoglobin concentration in Thai falciparum malaria. Am J Trop Med Hyg. 2001;65(4):335-7. [PubMed: 11693879]

6. Ratanapo S, Mungthin M, Soontrapa S, Faithed C, Siripattanapipong S, Rangsin R, et al. Multiple modes of transmission of giardiasis in primary schoolchildren of a rural community, Thailand. Am J Trop Med Hyg. 2008;78(4):611-5. [PubMed:18385357]

7. Warunee N, Choomanee L, Sataporn P, Rapeeporn Y, Nuttapong $\mathrm{W}$, Sompong $\mathrm{S}$, et al. Intestinal parasitic infections among school children in Thailand. Trop Biomed. 2007;24(2):83-8. [PubMed: 18209713]

8. Hesham MS, Edariah AB, Norhayati M. Intestinal parasitic infections and micronutrient deficiency: a review. Med J Malaysia 2004:59(2):284-93. [PubMed:15559182]

9. Olivares JL, Fernandez R, Fleta J, Rodriguez G, Clavel A. Serum mineral levels in children with intestinal parasitic infection. Dig Dis. 2003;21(3):258-61. doi: 10.1159/000073344. [PubMed: 14571100]

10. Culha G, Sangun MK. Serum levels of zinc, copper, iron, cobalt, magnesium, and selenium elements in children diagnosed with Giardia intestinalis and Enterobiosis vermicularis in Hatay, Turkey. Biol Trace Elem Res. 2007;118(1):21-6. doi: 10.1007/s12011-0070017-9. [PubMed: 17848727]
11. Wessells KR, Brown KH. Estimating the global prevalence of zinc deficiency: results based on zinc availability in national food supplies and the prevalence of stunting. PLoS One. 2012;7(11): e50568. doi: 10.1371/journal.pone.0050568. [PubMed:23209782]

12. Quihui L, Morales GG, Mendez RO, Leyva JG, Esparza J, Valencia ME. Could giardiasis be a risk factor for low zinc status in schoolchildren from northwestern Mexico? A cross-sectional study with longitudinal follow-up. BMC Public Health. 2010;10(1):85. doi 10.1186/1471-2458-10-85. [PubMed: 20170531]

13. Zarebavani M, Dargahi D, Einollahi N, Dashti N, Mohebali M Rezaeian M. Serum levels of zinc, copper, vitamin B12, folate and immunoglobulins in individuals with giardiasis. Iran J Public Health. 2012;41(12):47-53. [PubMed: 23641390]

14. Demirci M, Delibas N, Altuntas I, Oktem F, Yonden Z. Serum iron, zinc and copper levels and lipid peroxidation in children with chronic giardiasis. J Health Popul Nutr. 2003;21(1):72-5. [PubMed 12751677]

15. Yousef MI, El-Hendy HA, El-Demerdash FM, Elagamy EI. Dietary zinc deficiency induced-changes in the activity of enzymes and the levels of free radicals, lipids and protein electrophoretic behavior in growing rats. Toxicology. 2002;175(1-3):223-34. [PubMed 12049850]

16. Olivares JL, Fernandez R, Fleta J, Ruiz MY, Clavel A. Vitamin B12 and folic acid in children with intestinal parasitic infection. J Am Coll Nutr. 2002;21(2):109-13. [PubMed:11999537]

17. Celiksoz A, Acioz M, Degerli S, Alim A, Aygan C. Egg positive rate of Enterobius vermicularis and Taenia spp. by cellophane tape method in primary school children in Sivas, Turkey. Korean J Parasitol. 2005;43(2):61-4. [PubMed:15951641]

18. Ramana KV. Intestinal parasitic infections: An overview. Ann Trop Med Public Health. 2012;5(4):279. doi: 10.4103/1755-6783.101988.

19. Ertan P, Yereli K, Kurt O, Balcioglu IC, Onag A. Serological levels of zinc, copper and iron elements among Giardia lamblia infected children in Turkey. Pediatr Int. 2002;44(3):286-8. [PubMed 11982898]

20. Karakas Z, Demirel N, Tarakcioglu M, Mete N. Serum zinc and copper levels in southeastern Turkish children with giardiasis or amebiasis. Biol Trace Elem Res. 2001;84(1-3):11-8. doi: 10.1385 BTER:84:1-3:011. [PubMed: 11817681]

21. Sadraei J, Jabaraei J, Ghaffarifar F, Dalimi AH, Nikbakhtzadeh SM Vitamin B12 and Serum Mineral Levels in Children with Enterobius vermicularis Infection. Iran J Parasitol. 2007;2(1):35-8.

22. Escott-Stump S. Nutrition and diagnosis-related care.Philadelphia: Lippincott Williams \& Wilkins; 2012.

23. Khademi R, Ghaffarifar F, Asl HD. In vitro effect of folic acid and cobalamin (vitamin B12) on adhesion and growth of Giardia lamblia. Iran J Parasitol. 2006;1(1):47-52.

24. Sousa MC, Goncalves CA, Bairos VA, Poiares-Da-Silva J. Adherence of Giardia lamblia trophozoites to Int-407 human intestinal cells. Clin Diagn Lab Immunol. 2001;8(2):258-65. doi: 10.1128/ CDLI.8.2.258-265.2001. [PubMed:11238205]

25. Askari F, Ghaffarifar F, Asl HD, Haghi-Ashtiani MT, Delavari M. Study on variation of the sera folic acid, vitamin B12 and iron level in the 6-12 years old patients infected with Giardia lamblia in south Tehran [in Persian]. Iran J Pediatr. 2007;17(Suppl 2):149-54. 